\title{
Radiological Diagnostic Technique Selection in Early Cenvicat Lateral Stenosis
}

\author{
DOI: 10.17691/stm2017.9.2.14
}

Received March 29, 2017

K.A. Zhandarov, MD, PhD, Assistant, Department of Operative Surgery and Topographic Anatomy';

E.V. Ogarev, MD, PhD, Senior Researcher, Radiodiagnosis Department2;

A.N. Shcherbyuk, MD, DSc, Professor, Department of Operative Surgery and Topographic Anatomy ${ }^{1}$

11.M. Sechenov First Moscow State Medical University, 8/2 Trubetskaya St., Moscow, 119991,

Russian Federation,

2N.N. Priorov Central Scientific Research Institute of Traumatology and Orthopedics, 10 Priorova St.,

Moscow, 127299, Russian Federation

The aim of the investigation was to reveal the most reliable radiodiagnostic technique to detect an early dystrophic process and develop an algorithm to diagnose cervical lateral stenosis using radiology.

Materials and Methods. 80 case histories were studied by lateral stenosis imaging. We compared the radiographs and anatomical observations of the cervical spine ( $n=37$ ). All patients underwent survey radiography (radiography of spine) in two orthogonal views (AP and lateral), as well as in the oblique view, multispiral computed tomography (MSCT) on a helix CT machine LightSpeed VCT with 64 sections available per roentgen tube rotation, as well as magnetic resonance tomography (MRT).

Results. There have been defined the capabilities of radiodiagnosis and suggested the sequence of radiological methods used when examining patients with early cervical stenosis. MSCT with multiplanar and 3D reconstructions will be maximally informative in cervical lateral stenosis. The technique can be characterized as an informative one that can completely substitute radiological methods. Radiology in oblique views can be performed in patients with lateral stenosis in case MSCT is infeasible due to some reasons. MRT is required in case of marked neurological symptoms and differential diagnosis with acute hernias. An imaging algorithm of dystrophic impairments in early cervical lateral stenosis is the following: MSCT-radiography-MRT.

Key words: cervical spine; intervertebral canal opening; lateral stenosis of intervertebral canal; lateral canal.

At advanced stages of dystrophic processes in the cervical spine with lateral, combined or central stenoses, if there are persisting specific neurological and angiopathic symptoms requiring different therapy, patients undergo radiodiagnosis with high reliability of the process localization (accuracy of multispiral computed tomography (MSCT) and survey radiography is 91.2 and $74.5 \%$, respectively) [1]. There is no preferable and more reliable technique found to determine the dystrophic process localization in the cervical spine at early stages when there are the first complaints of radicular presentation [2]. There are the studies based on survey radiography, and such methods as magnetic resonance tomography (MRT) and MSCT are mentioned, however, there are no works, which could assess their capabilities, as well as there are no comparative data on choosing the best way to image early stenosis, it preventing from choosing the appropriate therapy.

The situation, thereby, determines the necessity to study the role of radiological methods to diagnose cervical lateral stenosis at early stages of the dystrophic process, and develop their selection algorithm. For this purpose we studied and summarized the literature data and the findings of our observations on lateral stenosis imaging [3].

The aim of the investigation was to reveal the most reliable radiodiagnostic technique to detect an early dystrophic process and develop an algorithm to diagnose cervical lateral stenosis using radiology.

Materials and Methods. The study was based on radiological findings of 80 patients, aged 35-65, with cervical osteochondrosis and the lateral stenosis signs.

The study was carried out in accordance with the Declaration of Helsinki (adopted in June 1964, Helsinki, Finland and revised in October 2000, Edinburgh, Scotland) and was approved by the Ethics Committee of I.M. Sechenov First Moscow State Medical University. All patients gave their informed consent.

The basic technique to study cervical spine was survey radiography (spondylography) in two mutually perpendicular views: AP and lateral. Spondylography in oblique views enables to determine the state of intervertebral foramina in degenerative dystrophic processes. The study was carried out on a stationary radiograph DM-BT-6 (South Korea).

For MSCT we used a helix CT machine LightSpeed

For contacts: Kirill A. Zhandarov, e-mail: Kirill-zhandarov@mail.ru 
VCT (General Electric, USA) with 64 sections available per roentgen tube rotation. The study was performed according a standard program using sections $0.6 \mathrm{~mm}$ thick. During the following stage we reconstructed multiplanar images on the operating station in various planes, as well as 3D image reconstructions.

MRT studies were carried out on a magnetic resonance tomograph Signa Excite HD (General Electric, USA), magnetic field intensity being 3 Tesla, in T1-WI, T2-WI, STIR modes in patients with degenerative dystrophic conditions of the cervical spine and radicular pain syndrome. The tomograph used makes it possible to reduce the section thickness up to $2 \mathrm{~mm}$ without image quality compromising. Moreover, it enables to image in three mutually perpendicular views: transverse (axial), frontal and sagittal. It is possible to image in oblique views as well. To solve the problems we used different pulse sequences: SE (spin-echo), FSE (fast spin-echo, the echo number was 17), FASE 100 (magnetic resonance myelography, the echo number being no more than 212).

Preliminary topographic anatomy study was carried out on 37 anatomical preparations, which included 185 intervertebral canals of cervical spine section complexes of patients aged $58-78$.

Results. The analysis of our own findings showed that early (I-II stages) dystrophic changes on survey radiographs can be considered only indirectly, oblique spondylograms enable to determine roughly the sizes of intervertebral foramina, the presence of marginal osteophytes in them. The advantage of radiography is availability, however, image quality and completeness of the pathology sings presented leave much to be desired.

Literature data and our own observations allow considering MSCT to be the most informative imaging technique in case of developing lateral stenosis. The key advantage of MSCT over other radiodiagnostic techniques in patients with lateral stenoses is the imaging of all details of pathological changes in vertebral bodies and intervertebral foramina. The modality enables to image all the structures involved lateral stenosis formation, and their $3 \mathrm{D}$ reconstruction. Less availability compared to radiography can be referred to the disadvantages of the method. MSCT has advantages over MRT, since on MRT scans marginal osteophytes have low imaging degree. In MRT, on T1-weighted image a signal is always more intensely colored in the central part, and has paler color in the periphery. MRT enables to estimate the morphological changes in lateral structures of spinal motion segment just indirectly: by epidural cellular tissue edema degree. In addition, the technique is costly and less available for patients.

We compared the initial morphometric parameters of intervertebral canal foramina according to topographoanatomical studies [4] and MSCT findings. By topographic anatomical study the following average parameters were found: external foramen (0.8-1.4), internal foramina $(0.4-0.8)$. According to MSCT the average parameters were the following: external foramen $(0.9-1.5)$, internal foramen $(0.5-0.9)$. The diameter varies, it increasing by $0.1 \mathrm{~cm}$. It seems to be reached by the fact that soft tissues are not seen on CT image causing errors.

Discussion. Lateral stenosis is the constriction of intervertebral canals resulting from degenerative dystrophic processes causing radiculopathy, with pathology aggravation due to reflex angiopathic syndrome of vertebral arteries [4]. The formation of marginal osteo-fibrous enlargement of bodies and transverse processes of vertebra is considered to occur alongside with fibrous changes of intervertebral disc. Fibrous dystrophy is accompanied by the invasion of blood vessels into the disc in the place of fibrous ring microfissures and hernia orifices rupture. Gradually, pulpal substance of a disc was replaced by connective tissue. During partial replacement of destroyed tissue of the intervertebral disc by connective tissue there was the enlargement of marginal osteophytes in the area of vertebral bodies and intervertebralis. These processes are compensatory and adaptive mechanisms in response to unstable spinal motion segment of the cervical spine due to hypermobility of the pulpal nucleus with partially lost fixation capability of the disc and developing disc fibrosis with the height decrease between the vertebral bodies [5]. As a result, frequently, persistent radicular pain syndrome develops, and it is the complaint patients refer to a doctor to diagnose a case. When intervertebral foramina are involved followed by chronic injuries of radicular structures and vertebral arteries, reflex angiopathic syndrome of vertebral arteries can occur. Due to lordosis in the cervical spine, the lower neck is under the maximal load: dystrophic changes with osteophytes occur there, primarily. Osteophytes can grow towards both: the spinal canal and the intervertebral foramina [6]. Our numerous observations prove this.

As early as in 1952 Saker suggested radiological anatomy classification of cervical osteochondrosis, which covers all the signs visualized on images. According to the classification, the signs of lateral sclerosis appear as early as at stage II of the process. The signs are as follows: subchondral sclerosis, compact anterior, posterior and posterolateral osteophytes, uncovertebral spondylarthrosis, constriction of intervertebral foramina. Stage III is characterized by marked subchondral sclerosis and marginal osteophytes, spondylarthrosis, constriction of intervertebral foramina. Stage IV presents bulk posterior osteophytes, spondylarthrosis, deforming uncoarthrosis, significant constriction of intervertebral foramina and spinal canal.

Most radiodiagnostic techniques of intervertebral osteochondrosis enable to reveal the presence and degree of the compression of spinal roots. Frequently, to reveal clinical manifestation of osteochondrosis, spinal radiography is administered, it accounting for $25-30 \%$ of all skeletal investigations [7]. In studies devoted to 
stenosis of lateral canals, the ossification processes are considered most frequently taking into account radiology and computed tomography.

Osteophytes first form on the posterior, then on the front or lateral side of the spinal motion segment, in peripheral areas of vertebral bodies, where the load on the intervertebral disc is maximum. Posteriorly oriented osteophytes traumatize radices in medial intervertebral foramina, and those oriented laterally injure the vertebral artery. It results in reactive subchondral sclerosis of endplates of vertebral bodies, semilunar (uncinate) processes, their sharpening followed by the rise of osteophytes at the edge of the processes [8]. The decrease in intervertebral disc height and coaptation of vertebral bodies are certain to result in size gain of osteophytes, they bearing against each other and going outside forming neoarthroses at the contact place (Luschka joints).

We examined 80 patients using anterioposterior and oblique radiography. Most cases were found to have significant enlargement of semilunar processes visible on oblique radiographs as an arcuate fissure above the semilunar process shadow, the enlarged transverse processes and vertebral bodies are clearly seen. Being guided by common characteristics of a degenerative process it is possible to interpret spondylograms to diagnose lateral stenosis. Spondylograms show all specific features: the stretching of cervical lordosis, intervertebral foramina constriction, marginal osteophytes of vertebral bodies, subchondral sclerosis with enlarged end plates, ossification of facet joints and uncovertebral arthrosis signs in the area of Luschka joints, the presence of narrowed intervertebral foramen due to lateral osteophytes, an arcuate fissure щель above the semilunar process shadow.

According to literature, MSCT accuracy is $16.7 \%$ higher compared to survey radiography [1], and no data is given on a preferable way of examining patients with early stenosis.

MSCT essentially extends the boundaries of radiography in cervical spine investigation. A computed tomography scanner shows lateral stenosis signs far better on both multiplanar reconstructions and also on 3D images [9]. Moreover, MSCT demonstrates most signs including indirect characterizing lateral sclerosis: an asymmetric increase in a disc diameter, the reduction of epidural cellular tissue volume due to epidural space obliteration, replacement or compression of nerve roots [10].

In addition to these signs, MSCT enables to determine the symptoms of intervertebral disc protrusion. Among these are the posterior border deformity of intervertebral disc in the form of its local bulging, the presence of soft tissue fragment in epidural space, deformed dural sac and the spinal marrow, subarachnoid space narrowing.

In patients with dystrophic changes of intervertebral discs the technique can also detect "a vacuum phenomenon": when a combination of gases in pressure change is released from interstitial fluid in the affected intervertebral disc, malabsorbed in its avascular tissue, and accumulates in the intervertebral space. The phenomenon is an objective sign of a rupture of fibrous ring of intervertebral disks [11].

The above-mentioned signs can help to differentiate so-called hard and soft hernias. Soft hernias are soft movable disc structures, while hard hernias due to a chronic process are secondarily calcified substance of an intervertebral disc and osteophytes [12]. Accordingly, clinical presentation will be due to the compression of roots or other structures of the spinal marrow, bone structures or fibrous substance of a disc, or their combination, and it is typical for lateral stenosis.

In addition, the same patients underwent MSCT $(n=80)$. On axial sections, in bone mode, there was determined the presence of marginal osteophytes constricting the lumen of both the spinal canal and intervertebral foramina (lateral canals) (Figure 1).

The second stage included multiplanar reconstructions of the images on the working station to specify the nature of degenerative changes and the stenosis degree of the spinal canal and intervertebral foramina at a certain level. Stenosis of lateral canals of the cervical spine is clearly seen on sagittal multiplanar reconstructions (Figure 2) and on $3 \mathrm{D}$ reconstructions (Figures 3, 4, 5). The latter enable to comprehend where a marginal osteophytes comes from (either from the body of the corresponding vertebra, or from a facet joint).

Comparison of radioanatomy findings provided that the size of medial bony foramina should be nearly the same, $\sim 0.7 \mathrm{~cm}$ [4], enables to diagnose in a patient lateral stenosis of intervertebral canals $\mathrm{C}_{I I I}-\mathrm{C}_{\mathrm{IV}}, \mathrm{C}_{\mathrm{IV}}-\mathrm{C}_{\mathrm{V}}$ leftward, along with other pathological manifestations of cervical osteochondrosis. Moreover, the alterations of the height change of intervertebral discs and their ossification are perfectly seen. $\mathrm{C}_{\mathrm{V}}-\mathrm{C}_{\mathrm{V}}$ intervertebral disc in a spinal motion segment is calcified (See Figures 3,4 ), along the periphery there are uncovertebral bony processes joining $\mathrm{C}_{\mathrm{V}}$ and $\mathrm{C}_{\mathrm{Vl}}$, posteriorly there is solid (ossified) hernia of $\mathrm{C}_{\mathrm{V}}-\mathrm{C}_{\mathrm{V}}$ intervertebral disk; it being consistent with the presentation of combined (lateral and central) stenosis and manifested in neurological symptoms. It should be mentioned, MSCT images show the so-called combined stenosis.

MSCT findings were compared with the nature of clinical (neurological) disorders in each individual, and in all cases the revealed MSCT alterations on the images were consistent with the clinical presentation. $3 \mathrm{D}$ reconstructions of images obtained on the working station enabled to specify the nature of stenosis of lateral canals at a certain level.

MSCT with multiplanar and 3D reconstruction is appropriate to diagnose both combined and also central and lateral stenoses. In suspected cases of central or combined stenosis it is better to perform MSCT with multiplanar reconstruction, sagittal views (See Figure 3) and $3 \mathrm{D}$ reconstructions, a frontal view (See Figure 5). 


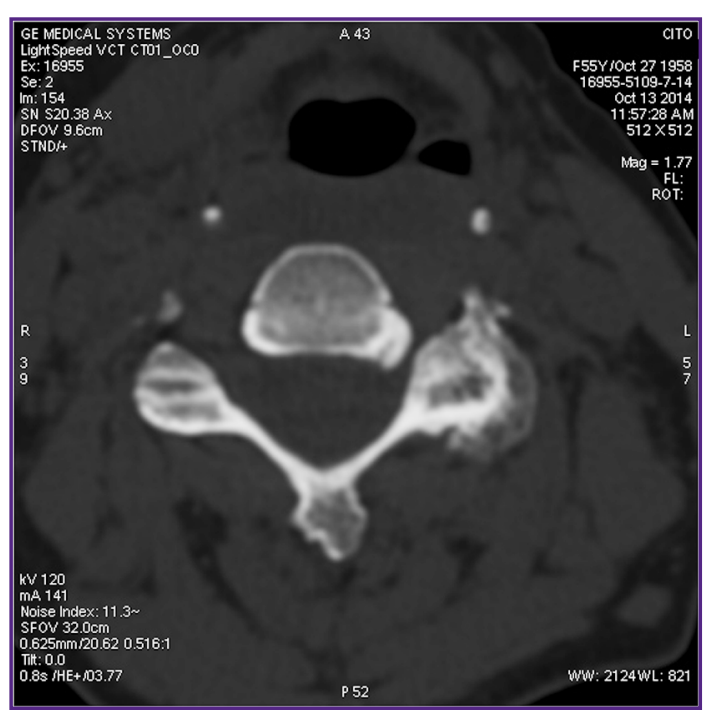

Figure 1. MSCT: axial section at the level of $C_{I V}-C_{v}$ intervertebral foramina; marginal osteophytes deform $C_{I V}-C_{V}$ intervertebral foramen on the left

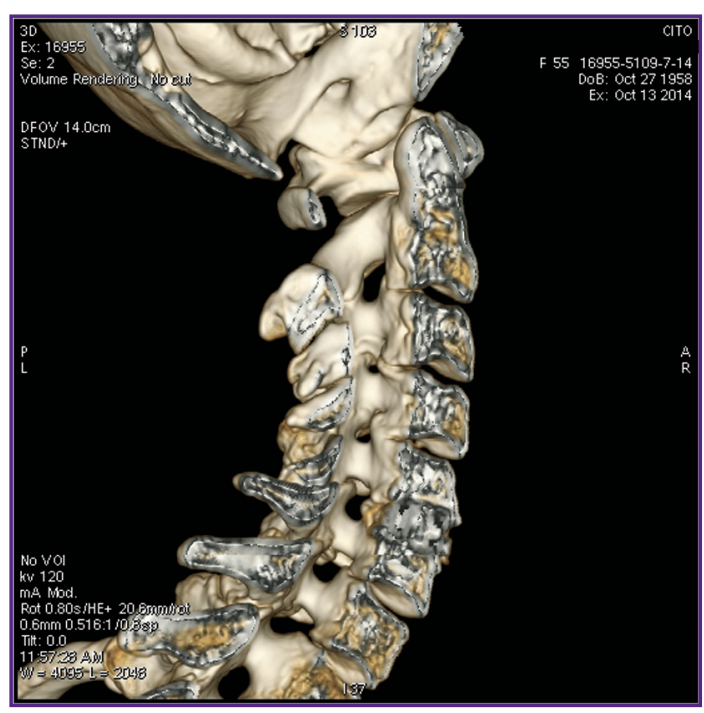

Figure 3. MSCT: 3D reconstruction image; the right spinal region is removed; stenoses of $\mathrm{C}_{\mathrm{III}}-\mathrm{C}_{\mathrm{IV}}, \mathrm{C}_{\mathrm{IV}}-\mathrm{C}_{\mathrm{V}}$ intervertebral foramina on the left on the part of the spinal canal are visualized

Diagnostic capabilities of MRT are demonstrated by the example of patient's examination in T1, T2-WI, STIR modes with section series in axial and sagittal views (Figures 6, 7). Physiological lordosis of the cervical spine is straightened on a series of magnetic resonance tomograms. Vertebral body height is not reduced. The adjoining arch laminae of vertebral bodies and the adjoining articular surfaces of intervertebral joints of the cervical spine are thickened and deformed due to marginal osteophytes (Figure 8).

On T2-WI intervertebral discs at the level of the

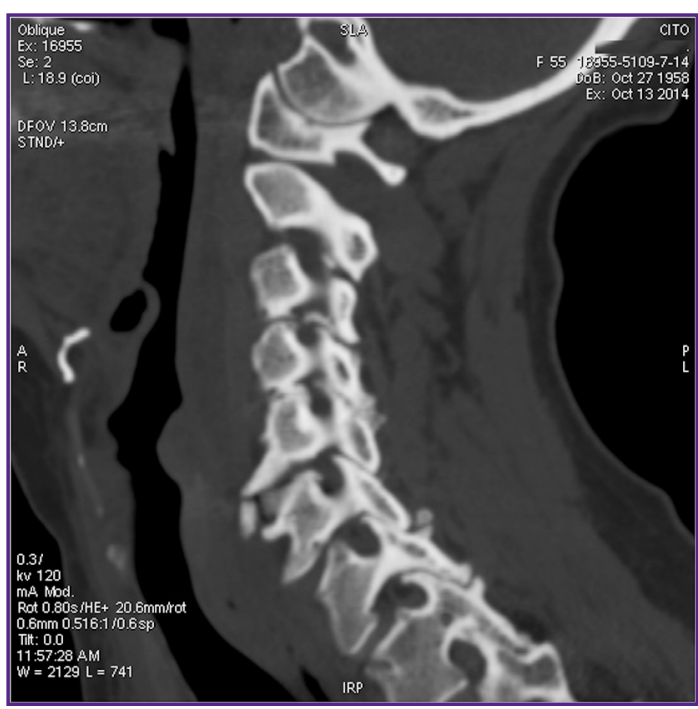

Figure 2. MSCT: multiplanar reconstruction, sagittal view; CT signs of marked osteochondrosis and spondyloarthrosis, stenoses of $C_{I I I}-C_{I V}, C_{I V}-C_{V}$ intervertebral foramina due to marginal osteophytes are visualized

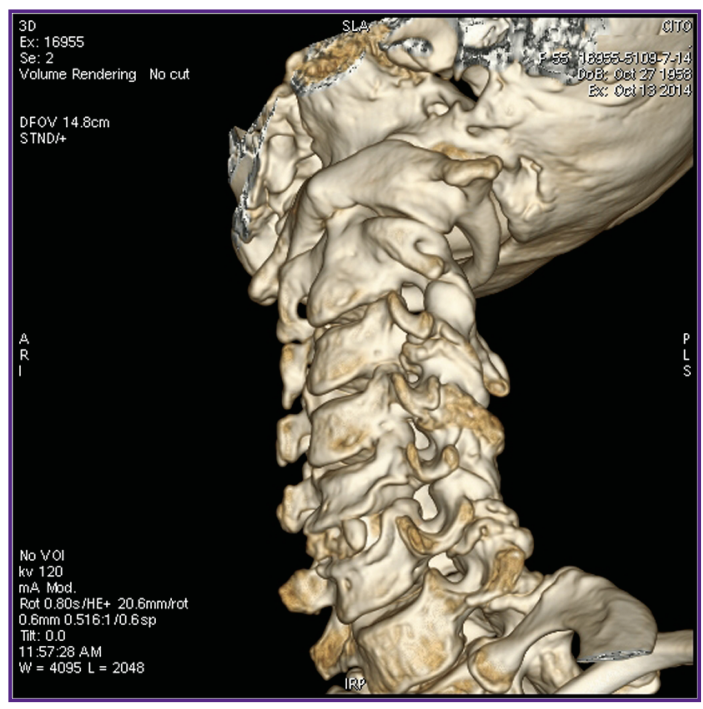

Figure 4. MSCT: 3D reconstruction image; stenoses of $C_{\mathrm{III}}-\mathrm{C}_{\mathrm{IV}}, \quad \mathrm{C}_{\mathrm{IV}}-\mathrm{C}_{\mathrm{V}}$ intervertebral foramina on the left; lateral view

pathology under study are reduced in height and signal intensity. There were revealed the protrusions of intervertebral discs of $\mathrm{C}_{\| 11}-\mathrm{C}_{\mathrm{IV}}$ (circular): up to $2.0 \mathrm{~mm}$, $\mathrm{C}_{\mathrm{IV}}-\mathrm{C}_{\mathrm{V}}$ (circular): up to $1.0 \mathrm{~mm}, \mathrm{C}_{\mathrm{V}}-\mathrm{C}_{\mathrm{VI}}$ (circular, more rightward): up to $2.0 \mathrm{~mm}, \mathrm{C}_{\mathrm{VI}}-\mathrm{C}_{\mathrm{VII}}$ (circular, more rightward): up to $2.0 \mathrm{~mm}$ towards the vertebral canal. The vertebral canal is deformed along the anterior contour and constricted at the level of protrusions of intervertebral discs (See Figure 7). Bone signal intensity at the study level is heterogeneous due to fat degeneration of bone tissue. Spinal marrow signal 


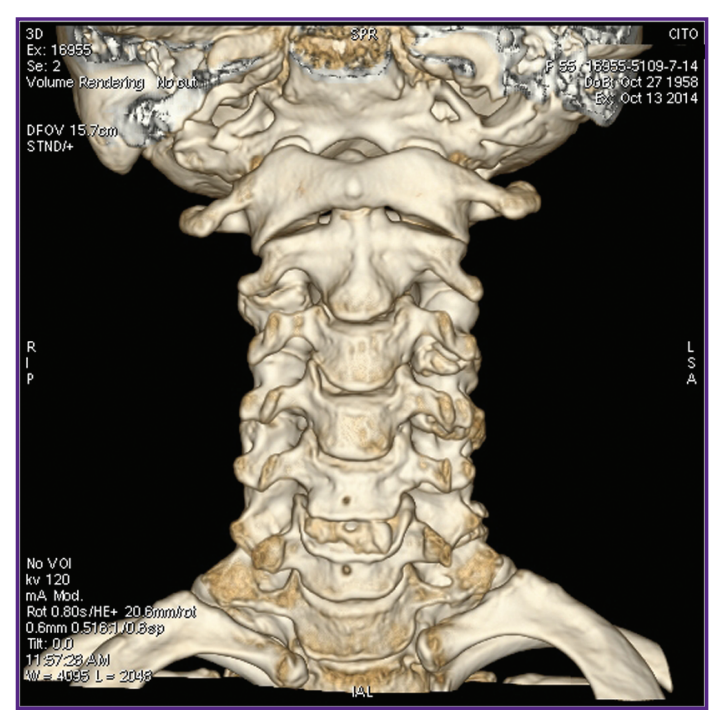

Figure 5. MSCT: 3D reconstruction image; frontal view

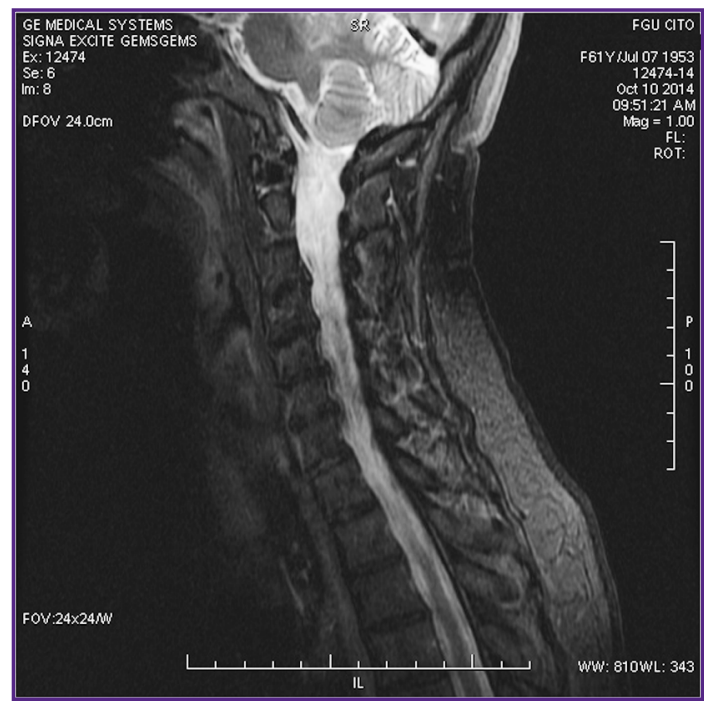

Figure 7. Cervical spinal MRT, sagittal view; protrusions of $\mathrm{C}_{\mathrm{III}}-\mathrm{C}_{\mathrm{IV}}, \mathrm{C}_{\mathrm{IV}}-\mathrm{C}_{\mathrm{V}}, \mathrm{C}_{\mathrm{V}}-\mathrm{C}_{\mathrm{VI}}, \mathrm{C}_{\mathrm{VI}}-\mathrm{C}_{\mathrm{VII}}$ intervertebral discs are visualized

intensity at the investigation level is not changed; central canal of spinal cord is visualized.

If it is necessary to study intraforaminal ligamentous apparatus, there is possibility to take oblique images as well. Presumably, the ligamentous apparatus is a factor of compressed spinal nerves and an etiological factor in intervertebral foramina ossification.

We studied ligamentous apparatus of intervertebral spinal by MRT in the sagittal plane, and at $\mathrm{C}_{\mathrm{IV}}-\mathrm{C}_{\mathrm{VII}}$ level - an angle of $30^{\circ}$ to the sagittal plane. Similar series of MRT examinations was performed within the framework of the research [13]. Live condition of soft tissues in lateral intervertebral foramina was assessed on a MRI scanner Flexart (Toshiba, Japan). Preliminary anatomical preparation of soft tissue structures in

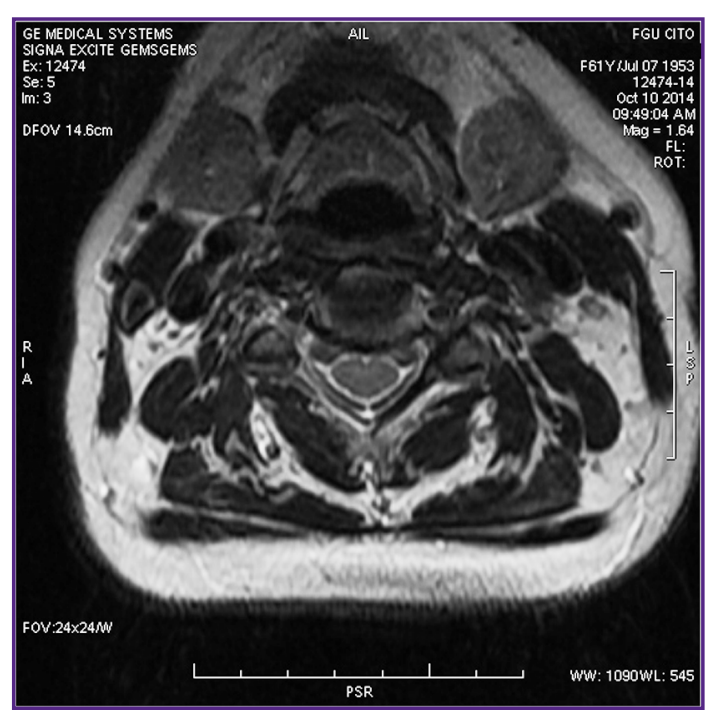

Figure 6. Cervical spinal MRT, axial view; the section at the level of intervertebral foramina

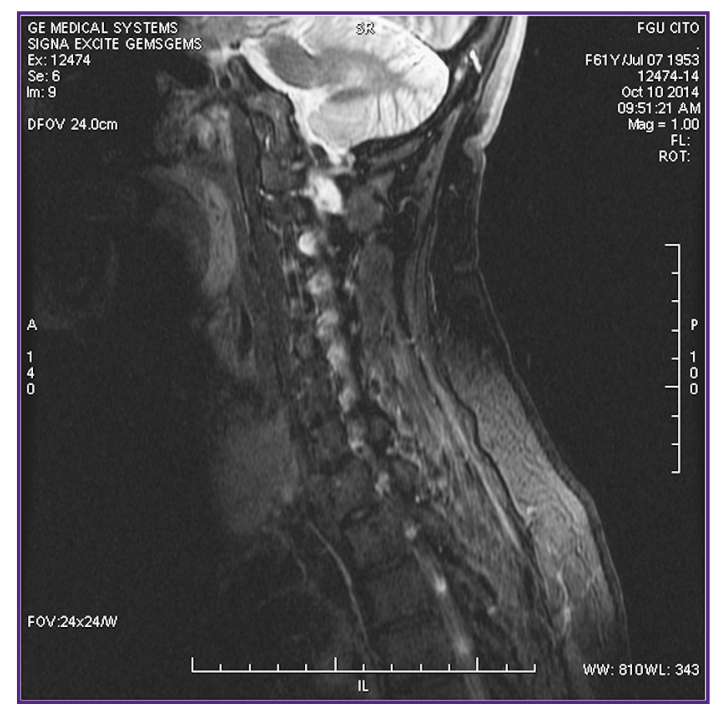

Figure 8. Cervical spinal MRT, sagittal view; the section at the level of intervertebral foramina

intervertebral foramina, in particular, in intraforaminal ligaments, was performed in an experimental part of the study to master the modes of magnetic fields, view directions, and section thickness [3]. Further, the ligaments in the area of lateral foramina of intervertebral canals were searched for in patients with degenerative and dystrophic diseases of cervical spine and radicular syndrome.

The mentioned techniques enabled to obtain both T1weighted images to study morphological spinal state and ligamentous apparatus, and also T2-weighted images to reveal pathological changes.

Currently, MRT is a basic method to diagnose spinal diseases. There are MRT advantages in revealing intervertebral disc pathologies. It is possible to 
detect early morphological changes of soft tissues of intervertebral discs, spinal marrow, its membranes and roots, the anterior and posterior longitudinal ligaments, joints. The process of degeneration and loss of fibrous ring fluid, pulpal nucleus and end plates are clearly observed. However, it should be noted that variable neuroimaging changes according to MRT are not always consistent with a neurological impairment degree [14].

Among the disadvantages in studying lateral vertebral structures by MRT there is the following feature: when interpreting magnetic resonance tomograms in T1images, an osteophyte appears to be hyperintensive in the central part, while on the periphery it is hardly imaged, therefore, it is difficult to diagnose early lateral stenosis by MRT.

Thus, the researches carried out enable to suggest the following diagnostic algorithm.

1. MSCT with multiplanar and $3 D$ reconstructions is maximum informative to study dystrophic involvements in lateral stenosis in the cervical spine. According to MSCT, morphometric sizes of intervertebral foramina in a topographic anatomical study and the indices of these sizes are comparable.

2. Radiography, oblique views, can be performed in patients with lateral stenosis in case MSCT is unavailable for some reason. This method can be recommended as that following MSCT.

3. MSCT completed with MRT is required in case marked acute neurological signs are present, for differential diagnosis with acute hernias providing combined stenosis, early (I-II) osteochondrosis, and if it is necessary to assess the condition of intervertebral discs or other soft tissue elements of a spinal motion segment.

Conclusion. There has been defined the algorithm of radiodiagnosis, which helps a doctor to differentiate the nature and degree of pathological changes in the cervical spine and choose the most appropriate therapy for early lateral stenosis that can improve substantially a patient's life quality. There has been suggested the following sequence of techniques to image dystrophic areas in patients with lateral stenosis of the cervical spine: MSCT-radiography-MRT.

Study Funding and Conflicts of Interest. The study was not funded by any sources, and the authors have no conflicts of interest related to the present study.

\section{References}

1. Rybin I.A. Indices of functional spinal radiography in choosing manual management and objectivation its efficiency in patients with neurological manifestations of osteochondrosis vertebralis. Novosti luchevoy diagnostiki 2000; 2(Suppl): 15.

2. Orel A.M., Lapteva N.V. The study of radiodiagnosis in assessment of posttraumatic spinal condition in post-whiplash syndrome. Manual'naya terapiya 2007; 4(38): 56-57.

3. Nikolaev A.V., Telpukhov V.I., Nelipa M.V., Zhandarov K.A. Structure of lateral channels of the spine cervical segment. Voprosy rekonstruktivnoy $i$ plasticheskoy khirurgii 2016; 2(57): 33-38, https://doi. org/10.17223/1814147/57/05.

4. Zhandarov K.A. Stenoz mezhpozvonochnykh kanalov sheynogo otdela pozvonochnika. Avtoref. dis. ... kand. med. nauk [Stenosis of intervertebral canals of cervical spine. PhD Thesis]. Moscow; 2016.

5. Tyulkin O.N., Shchedrenok V.V., Zakhmatova T.V., Kaurova T.A., Moguchaya O.V. Experience of surgical treatment for spinal canal stenosis in patients with degenerative cervical and lumbar spine diseases. Khirurgiya pozvonochnika 2011; 4: 58-68.

6. Ogleznev K.Ya., Stepanyan M.A., Sidorov E.V. Facet-syndrome in degenerative disease of cervical spine. Vertebronevrologiya 2000; 1-2: 38-43.

7. Smirnov V.V., Shavladze Z.N., Rakovskaya G.M., Savvova M.V., Shavladze N.Z. Radiodiagnosis of cervical osteochondrosis. Mezhdunarodnyy zhurnal eksperimental'nogo obrazovaniya 2015; 5-2: 179.

8. Pachuliya E.B. Kliniko-nevrologicheskaya i luchevaya diagnostika stenoza pozvonochnogo kanala. Avtoref. dis. ... kand. med. nauk [Clinico-neurological and radiological diagnosis of spinal canal stenosis. PhD Thesis]. Saint Petersburg; 2004.

9. Anosov N.A., Cheremisin V.M., Odinak M.M., Zhivolupov S.A. Informativity of helical computed tomography in differential diagnosis of thoracocervical radiculites. Vestnik Rossiyskoy voenno-meditsinskoy akademii 2004; 1(11): $68-75$.

10. Gushcha A.O. Diagnostika i khirurgicheskoe lechenie degenerativnykh kompressionnykh sindromov na urovne sheynogo otdela pozvonochnika. Avtoref. dis. ... dokt. med. nauk [Diagnosis and surgical treatment of degenerative compression syndromes of cervical spine. DSc Thesis]. Moscow; 2006.

11. Kariev M.Kh., Matmusaev M.M., Norov A.U. Surgical treatment of lumbar disk herniation in children and adolescents. Voprosy neyrokhirurgii im. N.N. Burdenko 2009; 3: 22-26.

12. Mikhailov A.N., Abelskaya I.S., Lukyanenka T.N. Comparative analysis of the importance of methods of radiology imaging in the characterization of bone structures vertebral segments with cervical osteochondrosis. Mezhdunarodnye obzory: klinicheskaya praktika i zdorov'e 2015; 4(16): 5-24.

13. Pestereva L.F. Magnitno-rezonansnaya tomografiya $v$ diagnostike stenoza mezhpozvonochnykh kanalov pri osteokhondroze poyasnichno-kresttsovogo otdela pozvonochnika. Avtoref. dis. ...kand. med. nauk Magnetic resonance tomography in diagnosis of intervertebral canal stenosis in lumbosacral osteochondrosis. PhD Thesis]. Moscow; 2001.

14. Hit' M.A., Nikitin S.S., Gushcha A.O. Role of transcranial magnetic stimulation in cervical spondilotic myelopathy. Annaly klinicheskoy i eksperimental'noy nevrologii $2012 ; 6(2): 23-26$. 